\title{
Fibromialgia e Infecção Crônica pelo Vírus da Hepatite C: Ausência de Associação em Duas Amostras
}

\section{Fibromyalgia and Hepatitis C Virus Chronic Infection: Lack of Association in Two Samples}

\author{
Luiz Severiano Ribeiro ${ }^{(1)}$, Austenir Maciel Coelho(2), Ana Flávia Madureira de Pádua ${ }^{(2)}$, \\ Leandro Lamas Dias ${ }^{(2)}$, Daniela Castelo Azevedo ${ }^{(2)}$, Fabiana de Miranda Moura $^{(2)}$, \\ Guilherme Santiago Mendes ${ }^{(3)}$, Helder Chaia Toledo Miranda ${ }^{(3)}$, Fernando Augusto Proietti ${ }^{(4)}$
}

\section{RESUMO}

Objetivo: avaliar a possível associação entre fibromialgia e infecção crônica pelo vírus da hepatite C (VHC). Métodos: estudo transversal com 186 pacientes fibromiálgicas e 55 pacientes com diagnóstico de doenças difusas do tecido conjuntivo (DDTC) não-fibromiálgicas, e em 33 pacientes com infecção crônica pelo VHC e 34 controles sem doenças infecciosas relacionadas ao fígado, todas do sexo feminino e de idade igual ou superior a 18 anos. A fibromialgia foi diagnosticada segundo os critérios classificatórios do American College of Rheumatology (ACR) de 1990. Infecção crônica pelo VHC foi definida pela presença do RNA do vírus por meio da reação em cadeia da polimerase (PCR). As demais variáveis consideradas para as manifestações extra-hepáticas associadas à infecção crônica compreenderam: fadiga, parestesias, fenômeno de Raynaud, sintomas de boca e/ou olhos secos, depressão e presença de títulos detectáveis de anticorpos antitireoidianos. Resultados: a infecção crônica pelo VHC foi detectada em três pacientes (1,6\%) do grupo fibromiálgico e em nenhuma das pacientes com o diagnóstico de DDTC $(\mathrm{p}=0,39)$. A dor musculoesquelética crônica disseminada foi mais prevalente no grupo de pacientes infectadas pelo VHC $(45,5 \%)$ do que no grupo-controle $(26,5 \%)$, mas não foi detectada associação entre fibromialgia e infecção crônica pelo VHC (OR = 1,39; IC 95\% $=0,43-4,57)$. Dentre as manifestações extra-hepáticas, apenas os sintomas relativos a boca e/ou olhos secos apresentaram uma associação com a infecção crônica $(\mathrm{OR}=6,40$; IC 95\% = 1,94$21,87)$. Conclusão: o estudo não detectou uma associação entre fibromialgia e infecção crônica pelo VHC.

Palavras-chave: fibromialgia, vírus da hepatite $\mathrm{C}$, infecção.

\begin{abstract}
Objective: to evaluate a possible association between fibromyalgia and hepatitis $C$ virus (HCV) chronic infection. Methods: crosssectional study comprising 186 fibromyalgic women, 55 nonfibromyalgic controls with a diagnosis of diffuse connective tissue diseases (DCTD), 33 HCV chronically infected women and 34 selected from the gastroenterology outpatient clinic with no liver related infection disease, all aged 18 or older. Fibromyalgia was diagnosed according to the American College of Rheumatology (ACR) classification criteria. Chronic HCV infection was defined by detection of $H C V$-RNA using the polymerase chain reaction (PCR). Other extra-hepatic manifestations comprised: fatigue, paresthesia, Raynaud's phenomenon, sicca symptoms, depression and detectable thyroid autoantibodies. Results: HCV-RNA was detected in 3 of the 185 fibromyalgic women (1.6\%) and in none of the 55 DCTD group ( $p=0.39$ ). Chronic widespread musculoskeletal pain was more prevalent in the infected group (45.5\%) than in the non-infected (26.5\%), but no association was found between fibromyalgia and $\mathrm{HCV}$ chronic infection $(O R=1.39 ; 95 \% C I=0.43-4.57)$. With the regard to other variables, only sicca symptoms were found to be associated with chronic infection $(O R=6.40 ; 95 \% C I=1.94-21.87)$. Conclusion: we found no association between fibromyalgia and chronic $\mathrm{HCV}$ infection.
\end{abstract}

Keywords: fibromyalgia, hepatitis $C$ virus, infection.

\footnotetext{
Recebido em 16/10/06. Aprovado, após revisão, em 14/03/07.

1-2. Serviço de Reumatologia do Hospital Governador Israel Pinheiro - IPSEMG, Belo Horizonte, Minas Gerais, Brasil

3. Serviço de Gastroenterologia do Hospital Governador Israel Pinheiro - IPSEMG, Belo Horizonte, Minas Gerais, Brasil

4. Departamento de Medicina Preventiva e Social, Faculdade de Medicina, Universidade Federal de Minas Gerais - UFMG, Belo Horizonte, Minas Gerais, Brasil.

1. Reumatologista do IPSEMG, doutorando em Saúde Pública, Área de Concentração em Epidemiologia da UFMG.

2. Residentes de Reumatologia do Serviço de Reumatologia do IPSEMG.

3. Gastroenterologistas do IPSEMG.

4. Professor-adjunto de Epidemiologia e Saúde Pública da Faculdade de Medicina da UFMG.

Endereço para correspondência: Luiz Severiano Ribeiro, Rua Teixeira de Freitas, 310/201, CEP 30350-180, Santo Antônio, Belo Horizonte, MG, Brasil,

e-mail: luizseveriano@terra.com.br
} 


\section{INTRODUÇÃO}

$\mathrm{O}$ vírus da hepatite $\mathrm{C}(\mathrm{VHC})$, um vírus RNA da família Flaviviridae, representa a principal causa da previamente denominada hepatite não- $A$, não- ${ }^{(1)}$. Desde a descrição e definição, em $1989^{(2)}$, tornou-se evidente sua associação com uma grande variedade de manifestações extra-hepáticas, inclusive desordens reumáticas e auto-imunes ${ }^{(3)}$.

É estimada uma prevalência em torno de 1,0\% para a infecção pelo VHC na população mundial ${ }^{(4)}$. Nos Estados Unidos, cerca de 2,7 milhões de pessoas estão infectadas pelo vírus. Dentre os fatores de risco para transmissão destacam-se, além da transfusão de sangue, o uso de drogas ilícitas, o comportamento sexual de alto risco e variáveis socioeconômicas representadas pelo grau de escolaridade e renda familiar. Não foi observada associação entre o risco de infecção e as variáveis demográficas designadas por sexo, idade e raça ${ }^{(5)}$.

A avaliação filogenética das seqüências do VHC investigadas em várias regiões geográficas sugere que existam pelo menos seis genótipos principais, designados pelos números de 1 a 6 , e pelo menos 30 subtipos, designados por letras minúsculas. Nos Estados Unidos, prevalecem os genótipos la $(60 \%)$ e lb (20\%). Os tipos 5 e 6 são mais encontrados no sudeste e sul da África. O tipo 4 é predominante na África Central e no Oriente Médio. No Brasil, predominam os genótipos la e $1 \mathrm{~b}(63 \%)$, e $3 \mathrm{a}(31,3 \%)^{(6)}$.

A infecção pelo VHC acarreta inflamação hepática e esteatose, podendo evoluir para fibrose hepática e cirrose em indivíduos cronicamente infectados, estes com grande risco de desenvolvimento de carcinoma hepatocelular. Essas complicações tardias ocorrem em um período, em geral, superior a 20 anos após o início da infecção. A infecção aguda pode passar clinicamente despercebida ou evoluir para hepatite fulminante. Aproximadamente 85,0\% das pessoas infectadas agudamente vão desenvolver uma viremia persistente, tornando-se, dessa forma, indivíduos infectados crônicos. A cirrose é pouco observada em pessoas que apresentam níveis persistentemente baixos das transaminases, mas a elevação destas não é representativa do grau de fibrose hepática. Dessa forma, a biópsia hepática representa o melhor indicador do estágio de evolução da doença, uma vez que gradua os componentes inflamatórios e o estágio de fibrose ${ }^{(1)}$.

As manifestações extra-hepáticas da infecção pelo VHC são as mais variadas possíveis. A infecção crônica está fortemente associada a crioglobulinemia mista essencial, glomerulonefrite membrano-proliferativa e porfiria cutânea tardia. De forma menos impressiva, encontra-se também associada a úlcera corneana de Mooren, líquen plano e fibrose pulmonar ${ }^{(7-14)}$.

A ocorrência de anticorpos antitireoidianos e hipotireoidismo tem sido relatada em associação com a infecção crônica em mulheres ${ }^{(14,15)}$.

A associação entre a infecção crônica pelo VHC, a presença do fator reumatóide e do anticorpo antinuclear (FAN), o fenômeno de Raynaud e doenças difusas do tecido conjuntivo (DDTC), como artrite reumatóide, lúpus eritematoso sistêmico, síndrome de Sjögren e vasculites sistêmicas, é relatada em alguns trabalhos ${ }^{(3,7,8,15-17)}$.

A fibromialgia também tem sido considerada como muito prevalente em pacientes infectados pelo VHC, especialmente mulheres ${ }^{(18-23)}$.

Para a avaliação da possível associação entre a fibromialgia e a infecção crônica pelo VHC em mulheres, foi realizado este estudo transversal. A inclusão da depressão e da ocorrência dos anticorpos antitireoidianos como variáveis de estudo deveu-se aos relatos da associação de ambas à infecção crônica ${ }^{(14,15,22)}$, bem como à demonstração da associação entre fibromialgia, auto-imunidade tireoidiana e depressão em pacientes do sexo feminino, conforme relataram os autores em estudo de $2004^{(24)}$.

A hipótese a ser aqui testada é a da inter-relação entre depressão e presença de anticorpos antitireoidianos, na associação entre fibromialgia e infecção crônica pelo VHC em mulheres, caso essa associação seja detectada.

A genotipagem do vírus e o estágio da doença hepática a partir da histologia, sempre que permitidos, foram correlacionados ao diagnóstico de fibromialgia nas pacientes infectadas. O tempo provável da infecção, o modo de infecção e o período de evolução da fibromialgia foram também analisados.

\section{PACIENTES E MÉTODOS}

\section{POPULAÇÃO ESTUDADA}

Os ambulatórios dos serviços de reumatologia e de gastroenterologia do Hospital Governador Israel Pinheiro - IPSEMG são referências para o atendimento de patologias reumatológicas e gastroenterológicas, respectivamente, dos servidores públicos do Estado de Minas Gerais.

As características sociodemográficas dos beneficiários assemelham-se ao perfil do funcionalismo público de outros Estados da Federação, compondo-se de uma maioria do sexo feminino $(67,0 \%)$, das quais $49,0 \%$ são docentes 
e 19,0\% não-docentes, com escolaridade superior a nove anos de educação formal ${ }^{(25)}$.

\section{SELEÇÃO DAS AMOSTRAS}

No período de fevereiro a junho de 2004, foram avaliadas, no ambulatório de reumatologia, 330 mulheres, para detecção de infecção crônica pelo VHC. Foram selecionadas 241 pacientes para essa amostra, composta por 186 pacientes fibromiálgicas e 55 não-fibromiálgicas com o diagnóstico de DDTC (primeira amostra).

Os diagnósticos de DDTC compreenderam: artrite reumatóide $(\mathrm{n}=24)$, lúpus eritematoso sistêmico $(\mathrm{n}=14)$, esclerose sistêmica $(n=7)$, polimiosite $(n=3)$, síndrome antifosfolípide primária $(\mathrm{n}=2)$, polimialgia reumática $(\mathrm{n}=2)$, síndrome de Sjögren primária $(\mathrm{n}=1)$, doença de Behçet $(\mathrm{n}=1)$ e policondrite recidivante $(\mathrm{n}=1)$.

Para compor a segunda amostra, foram selecionadas no ambulatório de gastroenterologia, nos intervalos compreendidos de agosto a novembro de 2005 e de março a setembro de 2006, 33 mulheres cronicamente infectadas pelo VHC.

No período de outubro de 2003 a fevereiro de 2004, foram selecionadas, desse mesmo ambulatório, 34 mulheres sem doenças infecciosas relacionadas ao fígado.

A amostra final foi, desse modo, composta por 67 mulheres, sendo 33 infectadas e 34 controles não-infectadas.

$\mathrm{O}$ modo de infecção pelo VHC ocorreu por via parenteral em 18 pacientes $(54,5 \%)$, das quais $16(48,5 \%)$ após transfusão de sangue, uma $(3,0 \%)$ após acidente com objeto perfurocortante, e uma $(3,0 \%)$ supostamente após tatuagem. Quinze pacientes $(45,5 \%)$ não apresentavam esses fatores de risco para contaminação. O tempo estimado de duração da infecção, calculado a partir da data de exposição às fontes parenterais, variou de sete meses a mais de 40 anos, com uma média de 19,8 anos. Biópsias hepáticas foram realizadas em 24 pacientes $(72,7 \%)$. Os dados da histologia revelaram variados estágios de fibrose e de atividade inflamatória, desde ausência de alterações, em três $(12,5 \%)$, a cirrose hepática, em cinco pacientes $(20,8 \%)$. $\mathrm{O}$ genótipo foi determinado em 14 pacientes: definido como lb em sete $(50,0 \%)$; la em três $(21,4 \%)$; 3 a em três $(21,4 \%)$; e indeterminado em uma $(7,1 \%)$.

Uma paciente apresentava co-infecção pelo vírus B da hepatite; e outra, pelo HIV. Outros diagnósticos encontrados foram: insuficiência renal crônica $(n=2)$, diabetes $(\mathrm{n}=2)$, líquen plano $(\mathrm{n}=1)$, psoríase $(\mathrm{n}=1)$, hipotireoidismo $(\mathrm{n}=1)$ e hipertensão arterial $(\mathrm{n}=12)$. Cinco pacientes $(15,2 \%)$ encontravam-se em tratamento com interferon e ribavirina.
No grupo-controle, foram computados os diagnósticos de hepatite auto-imune $(\mathrm{n}=4)$, cirrose alcoólica $(\mathrm{n}=2)$, colestase hepática $(\mathrm{n}=2)$, esteatose hepática $(\mathrm{n}=1)$, úlcera gástrica $(\mathrm{n}=1)$, hérnia de hiato $(\mathrm{n}=1)$ e síndrome do cólon irritável $(\mathrm{n}=17)$. Três pacientes apenas apresentavam queixas de dispepsia, e três não tinham diagnóstico definido. Outros diagnósticos computados foram: hipertensão arterial $(n=11)$, diabetes $(n=5)$ e hipotireoidismo $(n=4)$.

\section{DEFINIÇÃO DE CASO E CRITÉRIOS DE INCLUSÃO E EXCLUSÃO}

Para a primeira amostra, casos foram definidos como pacientes do sexo feminino com idade igual ou superior a 18 anos, com o diagnóstico de fibromialgia segundo os critérios do American College of Rheumatology (ACR) de $1990^{(26,27)}$ e sem DDTC concomitantes. Não-casos foram definidos como mulheres na mesma faixa etária, com os diagnósticos de artrite reumatóide, lúpus eritematoso sistêmico ou outras doenças do tecido conjuntivo, sem o diagnóstico concomitante de fibromialgia.

Para a segunda amostra, mulheres de idade igual ou superior a 18 anos, cronicamente infectadas pelo VHC, foram comparadas a controles gastroenterológicos não-infectadas. Foram excluídos todos os diagnósticos de doenças infecciosas relacionadas ao fígado.

Foram excluídas, em ambas as amostras, todas aquelas pacientes que, após leitura do consentimento livre e esclarecido, recusaram-se a participar do estudo.

O projeto foi aprovado pelo Comitê de Ética em Pesquisa do Hospital Governador Israel Pinheiro - IPSEMG (CEP-HGIP) em 8 de setembro de 2003.

\section{CÁLCULO AMOSTRAL}

O cálculo das amostras levou em consideração uma prevalência da infecção crônica pelo VHC, em pacientes do sexo feminino com o diagnóstico de fibromialgia, variando entre $5,0 \%$ e $30,0 \%$ em diferentes estudos da literatura $^{(18-23)}$; uma prevalência, variando entre $1,0 \% \mathrm{e}$ $11,0 \%$ da infecção crônica pelo VHC em pacientes com o diagnóstico de DDTC. Foram consideradas as prevalências observadas para a artrite reumatóide ${ }^{(28)}$ e o lúpus eritematoso sistêmico ${ }^{(16,17)}$, uma vez que representam as patologias mais freqüentes do grupo DDTC. Foi considerada a prevalência de $2,0 \%$ do diagnóstico de fibromialgia para o grupo-controle não-infectado. Levou-se em consideração a prevalência da fibromialgia na população americana maior de $18 \operatorname{anos}^{(29)}$. 
Estabelecido um poder de $80,0 \%$ e um nível de significância de $0,05 \%$, a comparação entre as proporções sugeridas possibilitou o cálculo das duas amostras que compõem o estudo.

\section{VARIÁVEIS DE ESTUDO}

O diagnóstico de fibromialgia foi computado na presença de dor musculoesquelética disseminada (abaixo e acima da cintura, à esquerda e à direita, com pelo menos um segmento do esqueleto axial) persistente por mais de três meses, na presença de 11 ou mais pontos dolorosos. Os pontos dolorosos foram examinados pela palpação manual com uma pressão aproximada de $4 \mathrm{kgf}^{(26)}$.

Para o diagnóstico de infecção crônica pelo VHC, após detecção dos anticorpos contra o VHC pelo teste imunoenzimático (ELISA) de $3^{\mathrm{a}}$ geração (Wiener lab. 2000 Rosario - Argentina), foi utilizado o teste qualitativo para a detecção do RNA do vírus, por meio da transcrição reversa do RNA-alvo para produzir DNA complementar (cDNA), amplificação do cDNA-alvo pela reação em cadeia da polimerase (PCR) e hibridização de ácidos nucléicos (AMPLICOR ${ }^{\circledR}$ HCV Test, version 2.0, Roche Diagnostics GmbH Mannheim, Germany).

As variáveis selecionadas para as manifestações extrahepáticas associadas à infecção crônica pelo VHC compreenderam: fadiga ("Você se sente cansada?"), parestesias ("Você sente dormências, formigamento ou agulhadas no corpo?"), fenômeno de Raynaud ("Já observou alterações na cor dos dedos, com palidez e/ou arroxeamento?") e sintomas de boca e/ou olhos secos ("Você sente a boca e/ou os olhos secos?"). Foram consideradas positivas as respostas "sempre" e "freqüentemente"(26,27). Além destas, foram avaliados o diagnóstico de depressão e a ocorrência de títulos detectáveis de anticorpos antitireoidianos.

Para os diagnósticos das DDTC, foram utilizados os critérios classificatórios mundialmente aceitos para cada patologia em particular ${ }^{(30-38)}$.

Para o diagnóstico de episódio depressivo maior atual ( $\operatorname{sim} /$ não), foi utilizado o MINI International Neuropsychiatric Interview (MINI) ${ }^{(39)}$, uma entrevista diagnóstica padronizada breve (15-30 minutos) compatível com os critérios do DSM-III-R/IV e da CID 10 $0^{(40-43)}$.

A auto-imunidade tireoidiana foi definida pela ocorrência de títulos detectáveis de anticorpos antiperoxidase da tireóide (anti-TPO) e/ou antitireoglobulina (anti-Tg) pela quimioluminescência (valores de referência $\geq 35 \mathrm{UI} / \mathrm{ml}$ para o anti-TPO, e $\geq 40 \mathrm{UI} / \mathrm{ml}$ para o anti-Tg), de acordo com as especificações do fabricante (IMMULITE ${ }^{\circledR} 2000$, EURO/DPC Ltd, UK).

As variáveis independentes sociodemográficas compreenderam a idade em anos, o estado civil (casada, nãocasada), a educação em anos de escolaridade $(<9$ anos, $\geq 9$ anos) e a renda mensal em número de salários mínimos ( $<5$ salários, $\geq 5$ salários) .

\section{ANÁLISE DOS DADOS}

$\mathrm{O}$ odds ratio (OR) com intervalo de confiança de 95\% (IC) foi utilizado para quantificar a magnitude das associações. As variáveis categóricas foram analisadas pelo teste do qui-quadrado. A única variável contínua foi a idade em anos, analisada pelo teste " $\mathrm{t}$ " de Student.

Utilizaram-se, para as análises, a versão 6.04 do Epi-Info e o Stata ${ }^{\circledR}$ Statistical Software $8.2^{(44,45)}$.

\section{RESULTADOS}

\section{ANÁlise da PRIMEIRA amostra (AmBUlatório de REUMATOLOGIA)}

Os dois grupos, fibromiálgicas e DDTC não-fibromiálgicas, foram comparáveis para as variáveis sociodemográficas consideradas: idade em anos, estado civil, educação e renda mensal (Tabela 1 ).

A prevalência da infecção crônica pelo VHC detectada na amostra completa foi de $1,2 \%$. As três pacientes cronicamente infectadas eram também fibromiálgicas, mas essa associação não apresentou significância estatística $(\mathrm{p}=0,39)$, tampouco a prevalência da infecção no grupo fibromiálgico $(1,6 \%)$ diferiu daquela estimada para a infecção na população mundial ${ }^{(4)}$.

Não foi detectada associação entre fibromialgia e autoimunidade tireoidiana. Por outro lado, foi detectada uma associação entre fibromialgia e depressão (Tabela 2).

\section{ANÁlise dA SEgunda amostra (AMBULATÓRIO DE GASTROENTEROLOGIA)}

As pacientes infectadas pelo VHC e o grupo-controle sem infecção foram comparáveis para as variáveis sociodemográficas selecionadas (Tabela 3 ).

Das manifestações extra-hepáticas avaliadas, apenas os sintomas de boca e/ou olhos secos apresentaram associação com a infecção crônica pelo VHC $(\mathrm{OR}=6,40$; IC 95\% = 1,94-21,87). A dor musculoesquelética crônica disseminada foi detectada como mais prevalente no grupo infectado $(45,5 \%)$ do que no controle $(26,5 \%)$, mas não se encontrou 
TABELA 1

DISTRIBUIÇÃO DE FREQÜÊNCIA DAS VARIÁVEIS SOCIODEMOGRÁFICAS PARA FIBROMIALGIA E DDTC. Ambulatório de Reumatologia, 2004

\begin{tabular}{l|c|c|c}
\hline Variável & $\begin{array}{c}\text { Fibromialgia } \\
\mathbf{n = 1 8 6}(\%)\end{array}$ & $\begin{array}{c}\text { DDTC } \\
\mathbf{n}=\mathbf{5 5}(\%)\end{array}$ & $\mathbf{p}^{*}$ \\
\hline $\begin{array}{l}\text { Idade } \\
\text { intervalo }\end{array}$ & $18-72$ & $34-80$ & \\
média & 52,6 & 55,2 & 0,98 \\
$\begin{array}{l}\text { Estado civil** } \\
\text { casadas }\end{array}$ & $111(60,99)$ & $25(45,45)$ & \\
não-casadas & $71(39,01)$ & $30(54,55)$ & 0,07 \\
$\begin{array}{l}\text { Educação** } \\
<9 \text { anos }\end{array}$ & $70(38,25)$ & $21(38,18)$ & \\
$\geq 9$ anos & $113(61,25)$ & $34(61,82)$ & 0,64 \\
Renda** & $111(60,99)$ & $34(61,82)$ & \\
$<5$ salários & $71(39,01)$ & $21(38,18)$ & 0,54 \\
$\geq 5$ salários &
\end{tabular}

* Valor de $p$, teste do qui-quadrado; ** sem informação (quatro para estado civil, quatro para renda e três para educação, no grupo de fibromiálgicas). Salário mínimo na ocasião: $\mathrm{R} \$ 240,00$.

\section{TABELA 2}

DisTRIBUIÇÃO DE FREQÜÊNCIA DAS VARIÁVEIS INFECÇÃO CRÔNICA PELO VHC, ANTICORPOS ANTITIREOIDIANOS E DEPRESSÃo PARA FIBROMIALGIA E DDTC. AMBULATÓRIO DE Reumatologia, 2004

\begin{tabular}{|c|c|c|c|c|}
\hline Variáveis & $\begin{array}{l}\text { Fibromialgia } \\
\mathrm{n}=186(\%)\end{array}$ & $\begin{array}{c}\text { DDTC } \\
\mathrm{n}=55(\%)\end{array}$ & $p^{*}$ & OR (IC 95\%) \\
\hline \multicolumn{5}{|l|}{ VHC } \\
\hline presente & $3(1,6)$ & 0 & & \\
\hline ausente & $183(98,4)$ & $55(100,0)$ & 0,39 & ? \\
\hline \multicolumn{5}{|c|}{$\begin{array}{l}\text { Anticorpos } \\
\text { antitireoidianos }\end{array}$} \\
\hline presente & $37(19,89)$ & $6(10,01)$ & & \\
\hline ausente & $149(80,11)$ & $49(89,09)$ & 0,13 & $2,03(0,75-5,76)$ \\
\hline \multicolumn{5}{|l|}{ Depressão } \\
\hline $\operatorname{sim}$ & $91(48,92)$ & $16(29,09)$ & & \\
\hline não & $95(51,08)$ & $39(70,91)$ & 0,01 & $2,33(1,16-4,74)$ \\
\hline
\end{tabular}

* Valor de $p$, teste do qui-quadrado.

\section{TABELA 3}

DISTRIBUIÇÃO DE FREQÜÊNCIA DAS VARIÁVEIS SOCIODEMOGRÁFICAS PARA CASOS DE INFECÇ̃̃O CRÔNICA PELO VHC E CONTROLES. AMBUlatório DE Gastroenterologia, 2003-06

\begin{tabular}{l|c|c|c}
\hline Variável & $\begin{array}{c}\text { Infecção pelo VHC } \\
\mathbf{n = 3 3}(\%)\end{array}$ & $\begin{array}{c}\text { Controles } \\
\mathbf{n = 3 4}(\%)\end{array}$ & $\mathbf{p}^{*}$ \\
\hline $\begin{array}{l}\text { Idade } \\
\text { intervalo }\end{array}$ & $37-77$ & $28-77$ & \\
$\quad$ média & 59,5 & 56,7 & 0,961 \\
Estado civil * & $11(35,5)$ & $14(41,2)$ & \\
$\quad$ casadas & $20(64,5)$ & $20(58,8)$ & 0,638 \\
não-casadas & $16(48,5)$ & $14(41,2)$ & \\
$\begin{array}{l}\text { Educação } \\
<9 \text { anos }\end{array}$ & $17(51,5)$ & $20(58,8)$ & 0,548 \\
$\geq 9$ anos & $26(78,8 \%)$ & $24(70,6 \%)$ & \\
Renda mensal & $7(2,1 \%)$ & $10(29,4 \%)$ & 0,441 \\
$<5$ salários &
\end{tabular}

* Valor de $\mathrm{p}$, teste do qui-quadrado; ** sem informação (dois para estado civil no grupo infecção pelo VHC). Salário mínimo variou de $\mathrm{R} \$ 240,00$ a $\mathrm{R} \$ 350,00$. associação entre fibromialgia e infecção crônica pelo VHC $(\mathrm{OR}=1,39 ;$ IC $95 \%+0,43-4,57)$.

A Tabela 4 sumariza a análise univariada para as manifestações extra-hepáticas computadas para a infecção crônica pelo VHC.

\section{TABELA 4}

ANÁlISE UNIVARIADA DAS VARIÁVEIS SELECIONADAS PARA INFECÇÃO CRÔNICA PELO VHC. AMBULATÓRIO DE GASTROENTEROLOGIA, 2003-06

\begin{tabular}{|c|c|c|c|c|}
\hline Variável & $\begin{array}{c}\text { Infecção pelo VHC } \\
n=33(\%)\end{array}$ & $\begin{array}{c}\text { Controles } \\
n=34(\%)\end{array}$ & OR (IC 95\%) & $p^{*}$ \\
\hline \multicolumn{5}{|l|}{$\begin{array}{l}\text { Dor } \\
\text { musculoesquelética }\end{array}$} \\
\hline disseminada & $15(45,5)$ & $9(26,5)$ & $1,81(0,57-5,78)$ & 0,26 \\
\hline Fibromialgia & $11(33,3)$ & $9(26,5)$ & $1,39(0,43-4,57)$ & 0,539 \\
\hline Fadiga & $13(39,4)$ & $18(52,9)$ & $0,58(0,19-1,72)$ & 0,266 \\
\hline Parestesias & $19(57,6)$ & $15(44,1)$ & $1,72(0,58-5,13)$ & 0,270 \\
\hline $\begin{array}{l}\text { Fenômeno } \\
\text { de Raynaud }\end{array}$ & $2(6,1)$ & $2(5,9)$ & $1,03(0,21-1,93)$ & 0,975 \\
\hline $\begin{array}{l}\text { Boca e/ou } \\
\text { olhos secos }\end{array}$ & $24(72,7)$ & $10(29,4)$ & $6,40(1,94-21,87)$ & 0,0004 \\
\hline Depressão & $11(33,3)$ & $16(47,1)$ & $0,56(0,18-1,71)$ & 0,252 \\
\hline $\begin{array}{l}\text { Anticorpos } \\
\text { antitireoidianos** }\end{array}$ & $5(17,2)$ & $5(14,7)$ & $1,32(0,28-6,17)$ & 0,689 \\
\hline
\end{tabular}

* Valor de $p$, teste do qui-quadrado; ${ }^{* *}$ sem informação (quatro para a presença de anticorpos antitireoidianos, no grupo infecção crônica pelo VHC).

Não foram detectadas diferenças em relação aos genótipos e dados da histologia entre fibromiálgicas e não-fibromiálgicas infectadas pelo VHC. A fibromialgia, no entanto, em todos os casos em que foi permitida uma relação temporal ocorreu após a infecção pelo VHC. $\mathrm{O}$ início dos sintomas de dor musculoesquelética em fibromiálgicas infectadas variou entre sete meses e dez anos, com uma média de 4,6 anos.

Também nessa amostra não foi detectada associação entre fibromialgia e auto-imunidade tireoidiana, mas houve associação entre fibromialgia e depressão $(\mathrm{OR}=4,38$; $\mathrm{IC}$ $95 \%=1,26-15,74)$.

\section{DISCUSSÃO}

O presente estudo não detecta associação entre fibromialgia e infecção crônica pelo VHC. Ao contrário de outras pesquisas $^{(18-23)}$, os resultados obtidos sugerem que o VHC, aparentemente, não desempenha nenhum papel na patogenia da fibromialgia, embora a falta de evidências aqui detectada não represente, necessariamente, a ausência da associação.

Os sintomas de dor musculoesquelética disseminada e fadiga, que freqüentemente acompanham as doenças viróticas, há muito despertam o interesse da pesquisa clínica para 
avaliação de possíveis associações entre infecções viróticas crônicas e síndrome de fibromialgia ${ }^{(46)}$. O que se constata, no entanto, é o fato de que as associações detectadas são sistematicamente refutadas em pesquisas subseqüentes.

O VHC vem sendo citado como possível fator determinante da fibromialgia. Mais uma vez, porém, em estudo recente, Narváez et al. ${ }^{(47)}$ contrariam essa informação, ao não encontrarem significância estatística entre a prevalência do VHC em uma população fibromiálgica e aquela estimada para a população geral.

No presente estudo, a prevalência da infecção crônica pelo VHC, detectada em mulheres fibromiálgicas $(1,6 \%)$, não diferiu daquela esperada na população mundial ${ }^{(4)}$. $\mathrm{Na}$ comparação entre mulheres cronicamente infectadas pelo VHC e não-infectadas, também não se observou uma associação com a fibromialgia, embora a dor musculoesquelética crônica disseminada fosse mais prevalente no grupo infectado. Mesmo se fossem utilizados critérios menos rígidos para o diagnóstico da fibromialgia ${ }^{(27)}$, essa associação não teria se confirmado.

Por outro lado, foi detectada, nas duas amostras, uma associação entre a fibromialgia e a depressão. É importante apontar para a elevada prevalência de depressão nessas amostras: fibromiálgicas $(48,9 \%)$, DDTC $(29,1 \%)$, infecção pelo VHC $(33,3 \%)$ e controle não-infectado $(47,1 \%)$. As elevadas taxas de depressão estão de acordo com a população fibromiálgica, em que é relatada uma prevalência de depressão que varia de $14,0 \%$ a $71,0 \%$ em algumas séries da literatura ${ }^{(48)}$. Também se pode dizer o mesmo em relação às elevadas taxas observadas para o grupo DDTC não-fi-

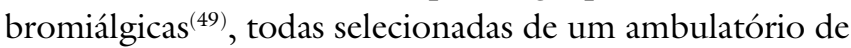
reumatologia, em que é observada elevada prevalência de dor crônica como principal queixa.

No grupo de mulheres cronicamente infectadas pelo VHC, era também esperada uma prevalência elevada de depressão(22). Já no grupo-controle não-infectado, esta não pode ser explicada em termos de uma patologia em comum, mas deve refletir as características inerentes à base de estudo selecionada. Não se deve desconsiderar, no entanto, a possível ocorrência de um viés de detecção, apesar de todos os cuidados em relação à utilização do instrumento (MINI) para o diagnóstico da depressão.

Mais importante, neste ponto da discussão, é o fato de que as determinações dessas taxas mantêm-se elevadas nos quatro grupos de pacientes considerados. Em estudos de base secundária com controles hospitalares, as amostras tendem a refletir características seletivas semelhantes entre casos e controles. Neste estudo, essas características podem ser representadas, além dos critérios de elegibilidade considerados a priori, por uma correlação entre depressão e procura por atenção médica.

A associação entre depressão e fibromialgia é bem reconhecida em várias séries da literatura ${ }^{(24,48-50)}$. Dentre os muitos fatores que levam o paciente fibromiálgico a procurar atenção médica, destaca-se a elevada ocorrência de desordem depressiva como condição clínica a ser mais bem investigada. Dessa maneira, as prevalências de depressão detectadas entre pacientes fibromiálgicos em estudos de base populacional e de base clínica diferem entre si, revelando taxas mais elevadas e pior prognóstico para o fibromiálgico de uma base clínica de estudo ${ }^{(49,50)}$.

Todavia, se considerada a menor prevalência como estimativa para a associação, esta será maior do que aquela esperada para a população geral, tanto em países desenvolvidos quanto naqueles em desenvolvimento ${ }^{(49,51)}$.

Dessa forma, as elevadas taxas detectadas para ocorrência da depressão e da fibromialgia, em especial no grupo-controle não-infectado, devem representar as características da base de estudo ambulatorial selecionada.

Em relação às outras variáveis clínicas de estudo, apenas os sintomas de boca e/ou olhos secos apresentaram-se associados à infecção crônica pelo VHC. A prevalência da síndrome de Sjögren não pôde, no entanto, ser computada devido à não-realização de exames oftalmológicos, biópsias labiais e testes sorológicos que pudessem confirmá-la.

Não se esperou abordar todas as variáveis clínicas e laboratoriais pertinentes à infecção crônica pelo VHC, tendo em vista as dificuldades de realização de exames laboratoriais extras impostas às pacientes no ambulatório de gastroenterologia. Na verdade, as perdas de informação referem-se, quase exclusivamente, aos exames laboratoriais requisitados para avaliação do fenômeno da auto-imunidade tireoidiana. Assim, desde a fase de planejamento da pesquisa, limitou-se o estudo a algumas variáveis clínicas de maior interesse e à pesquisa dos anticorpos antitireoidianos, consideradas imprescindíveis para a realização das análises sobre a associação questionada.

Em relação à única variável laboratorial estudada, a presença de títulos detectáveis de anticorpos antitireoidianos, não foi observada uma associação entre a presença destes e a infecção pelo VHC, nem entre esses anticorpos e a fibromialgia. Na primeira amostra, tal fato ocorreu devido a uma prevalência também elevada dos anticorpos, verificada em outras doenças auto-imunes ${ }^{(52)}$. Na segunda amostra, o tamanho desta foi insuficiente para tal detecção, além das perdas já mencionadas. 
Este estudo não detecta, portanto, associação entre fibromialgia e infecção crônica pelo VHC. Reforça, entretanto, as associações detectadas entre aquela e depressão( $24,49,50)$.

A questão a ser discutida sobre os resultados conflitantes acerca da associação entre fibromialgia e infecção pelo VHC pode ser parcialmente compreendida após a análise das pesquisas realizadas sobre o assunto. É fato que a fibromialgia constitui uma condição clínica freqüente ${ }^{(29)} \mathrm{e}$, em estudos não-controlados, pode ser detectada em um número por vezes expressivo de pacientes, por mera questão de chance. Isso é o que se observa nas séries de casos obtidas a partir de uma amostra de pacientes cronicamente infectados ${ }^{(8,19,21,23)}$.

Por outro lado, os estudos controlados ${ }^{(18,20,22)}$ podem sofrer uma série de vieses, que devem ser sempre considerados na sua interpretação.

No estudo em questão, as duas amostras foram calculadas a partir de dados da literatura para comparação de proporções, assegurados o poder e o nível de significância de ambas. No entanto, são amostras pequenas.

Não obstante, vários cuidados foram tomados para assegurar a comparabilidade de casos e controles, especialmente no que diz respeito ao princípio da base do estudo ${ }^{(53)}$. Definidas as duas amostras, assumimos que tanto casos quanto controles eram todos representativos da mesma experiência de base.

A escolha da amostra composta em sua totalidade por pacientes do sexo feminino limitou o seu tamanho, mas assegurou-nos que potenciais fatores de confusão, conhecidos e desconhecidos, relacionados ao sexo não interferiram nos resultados.

A adesão aos princípios acima citados ${ }^{(53-55)}$ aumenta a confiabilidade dos resultados, uma vez que os efeitos de-

\section{REFERÊNCIAS}

1. Thomas DL, Lemon SM: Hepatitis C. In: Mandell GL, Bennett JE, Dolin R, editors. Principles and practice of infectious diseases, $5^{\text {th }}$ ed. Philadelphia, Churchill Livingstone; 1736-60, 2000.

2. Choo Q-L, Koo G, Weiner AI, et al: Isolation of a cDNA clone derived from a blood-born non-A, non-B viral hepatitis genome. Science 244: 359-64, 1989.

3. Staub HL: Vírus $C$ da hepatite, manifestações sistêmicas e o reumatologista. Rev Bras Reumatol 38: 139-46, 1998.

4. Alter MJ: Epidemiology of hepatitis $\mathrm{C}$ in the West. Semin Liver Dis 15: 5-14, 1995.

5. Alter MJ, Kruszon-Moran D, Nainan OV, et al: The prevalence of hepatitis C virus infection in the United States, 1988 through 1994. N Engl J Med 19: 556-62, 1999.

6. Bassit L, Santos GR, Silva LC, et al: Genotype distribution of hepatitis C virus in São Paulo, Brazil: rare subtype found. Hepatology 29: 994-5, 1999. tectados têm menor chance de o terem sido por diferenças na seleção de casos e controles, distorcida por fatores de confusão ou por variabilidade das mensurações.

O estudo foi preparado de forma a eliminar ao máximo, dentro de suas próprias limitações, possíveis fontes de vieses, embora não se consiga eliminá-las de forma completa, o que seria ideal. Uma questão importante foi o número limitado de pacientes infectadas elegíveis para a pesquisa. Superou-se essa dificuldade ao atingir um tamanho de amostra adequado para as conclusões aqui discutidas. A detecção da depressão foi, também, uma possível fonte de viés, pelo fato de os observadores estarem sempre cientes dos diagnósticos de fibromialgia e infecção crônica pelo VHC.

A validade interna é presumida pelo fato de o perfil levantado para as variáveis sociodemográficas das amostras estar de acordo com aquele descrito para o servidor público estadual ${ }^{(25)}$.

Estudos prospectivos poderiam desvendar as associações ainda não reveladas entre fibromialgia e infecções viróticas crônicas, como a infecção pelo VHC. No entanto, tais estudos são praticamente inviáveis, devido à demanda de tempo e custos inerentes à sua realização. Estudos transversais com amostras suficientemente grandes para abordar essa questão seriam mais exeqüíveis e devem ser sugeridos, uma vez que representam o meio mais adequado para confirmação dos resultados aqui discutidos.

\section{AGRADECIMENTOS}

Os autores agradecem à professora de Língua Portuguesa Marilza Glaucia Dias Ribeiro, pela correção final do manuscrito.

\section{Declaramos a inexistência de conflitos de interesse.}

7. Wener MH, Johnson RJ, Sasso EH, Gretch DR: Hepatitis C virus and rheumatic disease (Editorial). J Rheumatol 23: 953-9, 1996.

8. Lovy MR, Starkebaum G, Uberoi S: Hepatitis C infection presenting with rheumatic manifestations: a mimic of rheumatoid arthritis. J Rheumatol 23: 979-83, 1996.

9. Liu F, Knight GB, Agnello V: Hepatitis C virus but not GB virus $\mathrm{C} /$ hepatitis $\mathrm{G}$ virus has a role in type II cryoglobulinemia. Arthritis Rheum 42: 1898-901, 1999.

10. Kerr GS, Rofail M, Lewis JH, et al: Prevalence of hepatitis C virus associated cryoglobulinemia at a Veterans Hospital. J Rheumatol 24: 2134-8, 1997.

11. Ferri C, Zignego AL: Relation between infection and autoimmunity in mixed cryoglobulinemia. Curr Opin Rheumatol 12: 53-60, 2000.

12. Daghestani L, Pomeroy C: Renal manifestations of hepatitis $\mathrm{C}$ infection. Am J Med 106: 347-54, 1999. 
13. Vassilopoulos D, Calabrese LH: Rheumatic manifestations of hepatitis C infection. Curr Rheumatol Rep 5: 200-4, 2003.

14. Killemberg PG: Extrahepatic manifestations of chronic hepatitis C. Semin Gastrointest Dis 11: 62-8, 2000.

15. Cacoub P, Poynard T, Ghillani P, et al: Extrahepatic manifestations of chronic hepatitis C. Arthritis Rheum 42: 2204-12, 1999.

16. Font J, Ramos-Casals M, Garcia-Carrasco M, et al: Hepatitis C virus infection in systemic lupus erythematosus. Study in a series of 134 patients. Arthritis Rheum 43: s251, 2000.

17. Barbosa VS, Silva NA, Martins RMB: Soroprevalência e genótipos do vírus da hepatite $\mathrm{C}$ em pacientes com lúpus eritematoso sistêmico (LES) em Goiânia, Brasil. Rev Bras Reumatol 45: 201-5, 2005.

18. Rivera J, De Diego A, Trinchet M, Garcia Monforte A: Fibromyalgia associated hepatitis $\mathrm{C}$ virus infection. $\mathrm{Br} \mathrm{J}$ Rheumatol 36: 981-5, 1997.

19. Buskila D, Shnaider A, Neumann L, et al: Musculoskeletal manifestations and autoantibody profile in 90 hepatitis $\mathrm{C}$ virus infected Israeli patients. Semin Arthritis Rheum 28: 107-13, 1998.

20. Buskila D, Shnaider A, Neumann L, Zilberman D, Hilzenrat $\mathrm{N}$, Sikuler E: Fibromyalgia in hepatitis $\mathrm{C}$ virus infection. Arch Intern Med 157: 2497-500, 1997.

21. Poynard T, Cacoub P, Ratziu V, et al: Fatigue in patients with chronic hepatitis C. J Viral Hepatitis 9: 295-303, 2002.

22. Gouding C, O'Connell P, Murray FE: Prevalence of fibromyalgia, anxiety and depression in chronic hepatitis $\mathrm{C}$ virus infection: relationship to RT-PCR status and mode of acquisition. Eur J Gastroenterol Hepatol 13: 507-11, 2001.

23. Loureiro M, Belloto E, Christmann RM, et al: Prevalência de fibromialgia em pacientes infectados com o vírus $\mathrm{C}$ da hepatite. Rev Bras Reumatol 42: 37-41, 2002.

24. Ribeiro LS, Proietti FA: Interrelations between fibromyalgia, thyroid autoantibodies, and depression. J Rheumatol 31: 203640,2004 .

25. Bittencourt RJ, Chaves SR, Amado RC, et al: Validação de inquérito de risco referido para vigilância em saúde de fatores de risco de doença arterial coronariana em servidores públicos estaduais de Juiz de Fora, Minas Gerais, Brasil. Cad Saúde Pública 20: 761-70, 2004.

26. Wolfe F, Smythe HA, Yunnus MB, et al: The American College of Rheumatology 1990 criteria for the classification of fibromyalgia: report of the multicenter criteria committee. Arthritis Rheum 33: 160-72, 1990.

27. Haun MVA, Ferraz MB, Pollak DF: Validação dos critérios do Colégio Americano de Reumatologia (1990) para classificação da fibromialgia em uma população brasileira. Rev Bras Reumatol 39: 221-30, 1998.

28. Maillefert JF, Muller G, Falgarone G, et al: Prevalence of hepatitis $\mathrm{C}$ virus infection in patients with rheumatoid arthritis. Ann Rheum Dis 61: 635-7, 2000.

29. Lawrence RC, Helmick CG, Arnett PC, et al: Estimates of the prevalence of arthritis and selected musculoskeletal disorders in the United States. Arthritis Rheum 41: 778-99, 1998.

30. Arnett FC, Edworthy SM, Bloch DA, et al: The American Rheumatism Association 1987 revised criteria for classification of rheumatoid arthritis. Arthritis Rheum 31: 315-24, 1988.
31. Hochberg MC: Updating the American College of Rheumatology revised criteria for the classification of systemic lupus erythematosus. Arthritis Rheum 40: 1725, 1997.

32. Vitali C, Bombardieri S, Jonsson R, et al: Classification criteria for Sjögren's Syndrome: a revised version of the European criteria proposed by the American-European Consensus Group. Ann Rheum Dis 61: 554-8, 2002.

33. Wilson WA, Gharavi AE, Koike T, et al: International consensus statement on preliminary classification criteria for definite antiphospholipid syndrome: report of an international workshop. Arthritis Rheum 42: 1309-11, 1999.

34. Masi AT, Rodnan GP, Medsger TA Jr, et al: Preliminary criteria for the classification of systemic sclerosis (scleroderma). Arthritis Rheum 23: 581-90, 1980.

35. Wortmann RL: Inflammatory diseases of muscle and other myopathies. In: Kelley WN, Harris Jr. ED, Ruddy S, Sledge CB, editors. Textbook of Rheumatology, $5^{\text {th }}$ ed. Philadelphia: WB Saunders, 1997. pp. 1177-206,

36. Hunder GG: Giant cell arteritis and polymyalgia rheumatica. In: Kelley WN, Harris Jr. ED, Ruddy S, Sledge CB, editors. Textbook of Rheumatology, $5^{\text {th }}$ ed. Philadelphia: WB Saunders, 1997. pp. 1123-32.

37. Hochberg MC: Relapsing polychondritis. In: Kelley WN, Harris Jr. ED, Ruddy S, Sledge CB, editors. Textbook of rheumatology, $5^{\text {th }}$ ed. Philadelphia: WB Saunders, 1997. pp. 1404-8.

38. International Study Group for Behçet's Disease: Criteria for diagnosis of Behçet's disease. Lancet 335: 1078-80, 1990.

39. Sheehan DV, Lecrubier Y, Sheehan KH, et al: The MINIInternational Neuropsychiatric Interview (MINI): The development and validation of a structured diagnostic psychiatric interview for DSM-IV and ICD 10. J Clin Psychiatry 59 (Suppl20): 22-33, 1998.

40. American Psychiatric Association: Diagnostic and statistical manual of mental disorders. $3^{\text {th }}$ edition, revised (DSM-III-R). Washington DC: American Psychiatric Association, 1987.

41. American Psychiatric Association: Diagnostic and statistical manual of mental disorders. $4^{\text {th }}$ edition (DSM-IV). Washington DC: American Psychiatric Association, 1994.

42. World Health Organization: International Classification of Diseases. 10 $0^{\text {th }}$ revision. Genebra: WHO, 1992.

43. Amorim P: MINI International neuropsychiatric Interview (MINI): validação de entrevista breve para diagnóstico de transtornos mentais. Rev Bras Psiquiatr 22: 106-15, 2000.

44. Dean AG, Dean JA, Coulombier D, et al: Epi Info. Version 6.0: a word processing database and statistics program for epidemiology on microcomputers. Atlanta: centers for Disease Control and Prevention, 1994.

45. StataCorp Stata Statistical Software: Release 8.2. College Station. TX: Stata Corporation, 2005.

46. Ribeiro LS, Proietti FA: Fibromialgia e estresse infeccioso: possíveis associações entre a síndrome de fibromialgia e infecções viróticas crônicas. Rev Bras Reumatol 45: 20-9, 2005.

47. Narváez J, Nolla JM, Valverde-Garcia J: Lack of association of fibromyalgia with hepatitis $\mathrm{C}$ virus infection. J Rheumatol 32 : 1118-21, 2005. 
48. Macfarlane GJ, Morris S, Hunt IM, et al: Chronic widespread pain in the community: the influence of psychological symptoms and mental disorder on healthcare seeking behavior. J Rheumatol 26: 413-9, 1999.

49. Okfuji O, Turk DC, Sherman JJ: Evaluation of the relationship between depression and fibromyalgia syndrome: why aren't all patients depressed? J Rheumatol 27: 212-9, 2000.

50. Aaron LA, Bradley LA, Alarcón GS, et al: Psychiatric diagnoses in patients with fibromyalgia are related to health care-seeking behavior rather than to illness. Arthritis Rheum 39: 436-45, 1996.

51. Vorcaro CMR, Lima-Costa MFF, Barreto SM, Uchoa E: Unexpected high prevalence of 1-month depression in a small Brazilian community. The Bambuí Study. Acta Psychiatr Scand 104: 257-63, 2001.
52. Larsen PR, Davies TF, Hay ID: The thyroid gland. In: Wilson JD, Foster DW, kronenberg HM, Larsen PR, editors. Williams Textbook of endocrinology, $9^{\text {th }}$ edition. Philadelphia: WB Sauders, 1998. pp. 389-515.

53. Wacholder S, McLaughlin JK, Silverman DT, Mandel JS: Selection of controls in case-control studies I. Principles. Am J Epidemiol 135: 1019-28, 1992.

54. Wacholder S, Silverman DT, McLaughlin JK, Mandel JS: Selection of controls in case-control studies II. Types of controls. Am J Epidemiol 135: 1029-41, 1992.

55. Wacholder S, Silverman DT, McLaughlin JK, Mandel JS: Selection of controls in case-control studies III. Design options. Am J Epidemiol 135: 1042-50, 1992. 